\title{
FROM THE DESERT TO THE EDGE OF SPACE
}

\section{Not all NASA launches need rockets and countdowns. Eric Hand sees the alternative in Fort Sumner, New Mexico.}

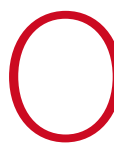
$n$ the day of the launch Mark Cobble arrives well before dawn. Lightning studs the sky on the horizon; halogen spotlights bathe the three-story NASA hangar in light. The desert around Fort Sumner municipal airport in New Mexico is still, its silence relieved only by the hum of a generator, the clapping of an exhaust flap on a helium truck and the slight rustle of the wind in the scraggly trees and scrub. That windy rustle bothers Cobble, the NASA crew chief in charge of the launch that is about to get under way.

Since 02:30 the airport manager has been sending up weather balloons the size of beach balls every half hour or so. Ross Hays, a former CNN weatherman now with NASA, has been on site since 01:00 to gather weather data, armed with two flasks of coffee and the peanut butter and jelly sandwiches he reserves as a treat for 'show days'.

"No chance of precip?" Cobble asks.

"Nope," says Hays, an optimist. "It's all over in the panhandle. It's all clear over New Mexico."

Cobble looks at the weather data gleaned from the Air Force, the National Weather Service and a network of instruments at public high schools. He strokes his chin. The wind is definitely worrisome. But the weather is only going to worsen as the week goes on. "We'll see how it goes and hope for the best," he finally says. "I'll get 'em started."

If your image of a NASA launch is a mission control room full of computers, pocket protectors and neck-ties, think again. This is countryand-western NASA, all boots and blue jeans; the tools of the trade are Buck knives, duct tape, parachute cord and patience, plus a whole lot of helium. And the 'spacecraft' hang beneath balloons.

Balloons have long offered a cheap alternative to rocketry. Even if by their very nature they cannot rise above the atmosphere, they can still rise above $99 \%$ of it, leaving dust, weather
"They have to prove the technology before people start to take them seriously." - Simon Swordy year it was just 17 . This is partly explained by the changing nature of the experiments and observations that astrophysicists want to make. Those that could be performed easily and quickly the low-hanging fruit for telescopes 30 kilometres up in the sky - have been done. Now, most experiments require longer flights and more complicated instruments. And this is where a new sort of balloon comes in - the peculiarly pumpkinshaped balloon folded up and wrapped in protective red plastic in the Fort Sumner hangar, which Cobble and his crew from NASA's Columbia Scientific Balloon Facility (CSBF) are about to and water vapour behind. In the 1980s, NASA was launching 80 balloons a year as part of its programmes in astronomy and atmospheric chemistry: balloon mounted telescopes weighing a tonne or more have made some remarkable discoveries - and remarkable recoveries. Unlike their brethren on satellites, sensors that fly beneath balloons can be used again and again, although getting them back from windblown landing sites can be a trial.

Since the 1980s, though, the number of NASA balloons launched has steadily declined. Last launch. Its fabric, as thin as the plastic of a refuse bag, will, when inflated and aloft, measure 54 metres across and have the volume of more than 600 double-decker London buses. And if all goes well, it will provide a solution to the abiding problem of scientific ballooning - that what goes up comes down all too soon. According to its designers, this style of a balloon can stay up night and day for months at a time.

All scientific balloons are filled with helium. In

\section{Where balloons have made advances}

\section{Cosmic microwave} background

In 1998, a project called Balloon Observations of Millimetric Extragalactic Radiation and Geophysics (BOOMERanG) made a fine-scale map of the cosmic microwave background over a part of the sky and provided evidence for its 'flatness'. A follow-up flight in 2003 was able to detect some polarization in the background - consistent with a period of 'inflation' in the very early cosmos.

\section{Antiparticles}

The Balloon-borne Experiment with a Superconducting Spectrometer (BESS) made nine 1-day flights in 1993-2002 and detected more than 2,400 antiprotons, thus contributing $80 \%$ of the records of incoming antimatter. More recent longer flights revealed constraints on the presence of anti-helium. The instruments rival the sensitivity of the $\$ 1.5$-billion Alpha Magnetic Spectrometer - still awaiting a ride to the International Space Station.
Supernova 1987a

When the most spectacular supernova in centuries exploded while America's space shuttles were grounded, a detector that might have flown on the shuttle was launched on a balloon from Antarctica. Although that pioneering effort failed, several balloon missions in Australia over the following two years detected rays from the explosion, confirming theories about the radioactive decay of the star's remains.

\section{Getting high} the more-normal balloons, sometimes called zero-pressure balloons, this buoyant helium is at the same pressure as the atmosphere outside, and the balloon's volume thus changes with the temperature. This means that if it is to retain its altitude, the balloon may need to vent gas by day and drop ballast by night. This limits the mission lifetime, normally to days. In steady conditions such as the constant daylight of a polar summer balloons can stay up longer; in 2005 a NASA balloon circled Antarctica three times in a record 42-day flight. But although that is long enough for astrophysicists looking at things such as cosmic rays to get good data, longer would be even better. Immunity to the day-night cycle would also allow missions to fly from more accessible places than Antarctica, and would make things easier for observers who like to do it in the dark.

The balloon being launched at Fort Sumner is designed to provide these benefits by 
号 maintaining a constant volume as opposed to constant pressure. The gas inside will at times 3 be at a higher pressure than the atmosphere

outside, which is why such designs are called 'super-pressure' balloons. The pressure changes are absorbed by high-strength tendons in the balloon's ribs made from Zylon, a polymer also used to protect racing-car cockpits. NASA scientists think super-pressurized balloons like this could stay aloft for 100 days or more (see graphic, overleaf). Because they are less vulnerable to diurnal cycles they also open up the possibility of multiple trips around Earth at mid-latitudes. That opens up more of the sky to observation, and lets strictly nocturnal astronomers into the game too.

\section{Outperforming satellites}

More time, more sky; more night-time sky, more sky all year round. In terms of science per dollar, super-pressure balloons might well outperform satellites for a far wider range of missions than the current technology allows. "There are a lot of people waiting for this technology to become mature enough," says Simon Swordy, director of the Enrico Fermi Institute at the University of Chicago, Illinois, who wants to use balloons to study the history of cosmic rays in the Milky Way. "But they have to prove the technology before people in NASA start to take them seriously," he says.

Providing that proof is hard. The arguments in favour of super-pressure balloons have been around for a while; Nature reported on them enthusiastically five years ago (see Nature 421, 308-309; 2003). But flight success has proved elusive. The test at Fort Sumner is part of the latest attempt to do something about that. Failure could jeopardize an increase in NASA's planned budget for scientific balloons, which calls for spending on balloons to inflate by $50 \%$ over the next four years, in part so as to be ready to take advantage of super-pressure technology as it moves from understandably temperamental prototype to work horse. Too much temperament, though, and the programme will founder. The test flights have to go well. And the New Mexico weather has to cooperate with Cobble.

By 06:00 Cobble has his team hard at work. Big Bill, the 45-tonne truck that tethers the balloons until the last moment, lumbers out to a patch of cracked, weedy pavement. The sky has blossomed from black to blue to pink, and the rising sun reveals wind turbines ticking over on a distant ridge - not an encouraging sign for the balloon launchers. Danny Ball, Cobble's boss and the director of the CSBF, in Palestine, Texas, points to a small weather balloon on a long leash that the wind is pulling out at a $45^{\circ}$ angle. "That's about 18 knots on it right now," Ball says. "That's way, way too much." While

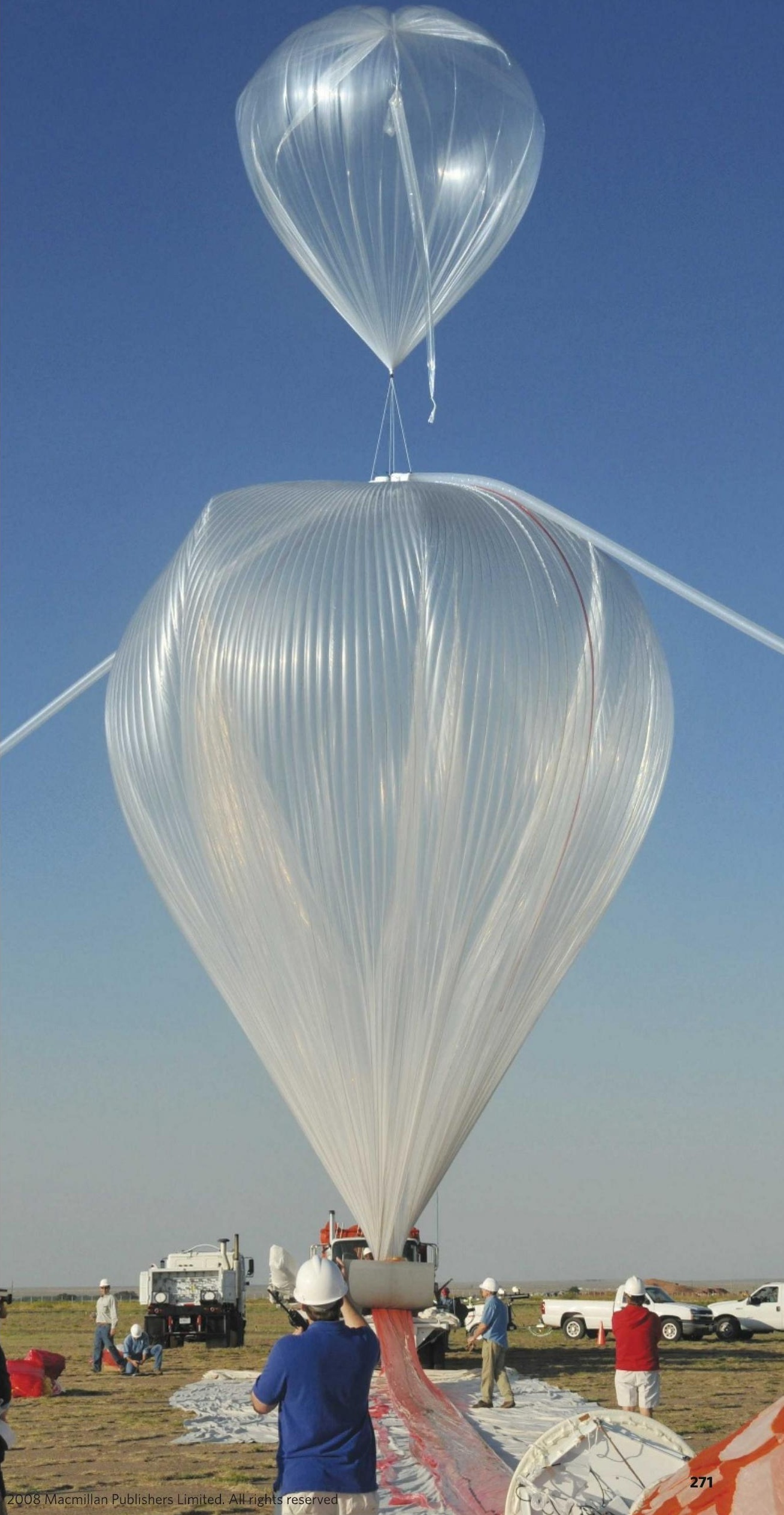




\section{SATELLITES}

Cost: More than $\$ 10$ million

Duration: Years

Slow to build and expensive

satellites gather years worth of data

with no atmospheric interference.

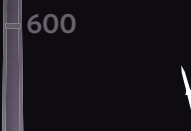

SOUNDING ROCKETS

Cost: $\$ 1.5$ million

Duration: 15 minutes

Quick up-and-down flights, to altitudes anywhere between 30 and 1,500 kilometres, provide training for young investigators, and explore regions too high for balloons and too low for satellites. But flights are very short.

200

\section{ZERO-PRESSURE BALLOONS}

Cost: $\$ 250,000$

Duration: Up to 30 days

Flying three times higher than aeroplanes, stratospheric balloons collect data above $99 \%$ of the obscurants in the atmosphere. Zero-pressure balloons contain an open valve. Daily temperature swings cause losses in altitude that can be compensated by ballast drops for several weeks. But long flights are limited to summers at the poles, where temperatures are nearly constant.
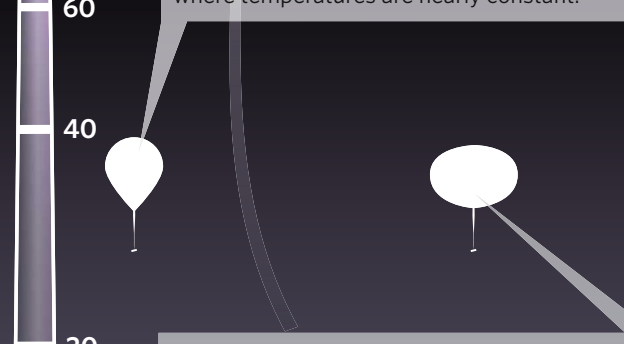

20

\section{SUPER-PRESSURE BALLOONS}

10

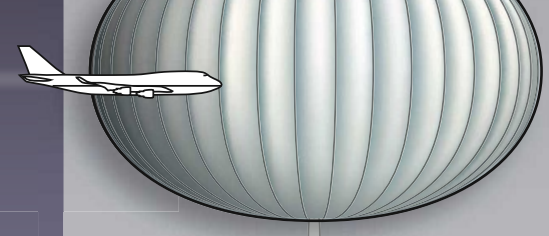

6

Cost: $\$ 1.5$ million

Duration: 100 days or more

The next generation design in scientific ballooning, super-pressure balloons are completely sealed. Tendons in the pumpkin-shaped balloon absorb pressure changes caused by temperature swings. The balloons dwarf a Boeing 747 aeroplane, but, as the indicators show, fly much higher. Flights could circle Earth at mid-latitudes for months; more of the Universe could thus be observed during both day and night. the launch team peels the balloon from its banana-skin wrapping and checks for tears and twists, Ball paces in a red-hooded sweatshirt, shorts and sandals. He frequently cups his hands against the wind to light cigarettes that he then throws away half smoked.

All of NASA's balloon launches come under Ball's jurisdiction and he embodies the programme's blue-collar culture: gruff and given to a blunt common sense. Before ballooning he worked on offshore drilling barges in the Pacific Ocean. "The satellite scientists work in clean rooms with 10-year development cycles and unlimited reviews," he says, as the crew lays out the wrapped balloon behind Big Bill. "We don't have clean rooms. We don't do any of that"

\section{More bang for the buck}

The difference is reflected in the price. Most of the satellites that hold, stabilize and power scientific instruments are made by aerospace companies such as Boeing or Lockheed Martin for tens of millions of dollars, at the cheapest. The same companies, and some others, sell rocket launches at similar prices. NASA's balloons, on the other hand, are glued together for US $\$ 250,000$ a time on the work tables of Aerostar, of Sulphur Springs, Texas, a facility that has at times sold left-over polyethylene film for refuse bags. The tougher skin and tendons that go into super-pressure balloons make them cost a fair bit more - about $\$ 1.5$ million - but nothing near the cost of a satellite launch. The most expensive parts of such missions are the instruments themselves, which are often exactly the same as those that will fly on the satellite missions they foreshadow. But below a balloon they can be flown in simple gondolas hanging from steel cables; no need for the thermal insulation or the hi-tech components in satellite buses. Ball even recalls flying an instrument still supported by the workbench on which it was built.

Price is not the only difference. Compared with the fairly fast turnaround culture of the balloons, satellite development is sluggish and risk averse. Instruments can fly on balloons years before their equivalents or descendants fly in space (see 'Where balloons have made advances'). In 1998, the Balloon Observations of Millimetric Extragalactic Radiation and Geophysics (BOOMERanG) experiment studied the cosmic microwave background in part of the sky, finding important evidence for the 'flatness' of the

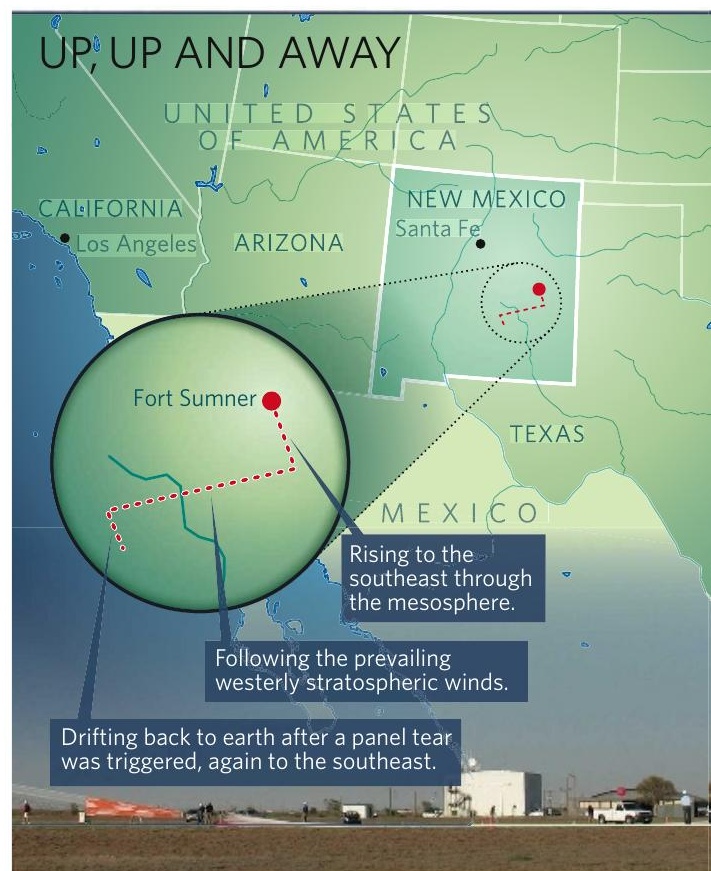

Universe and scooping some of the results from the later and much more expensive Wilkinson Microwave Anisotropy Probe. Later this year, when the European Space Agency's €600million (\$940-million) Planck spacecraft starts to map the whole-sky background it will be using instruments of the same design.

According to Andrew Lange, an astrophysicist at the California Institute of Technology in Pasadena who was on the BOOMERanG team, a balloon could fly something much more impressive today. He has plans for an instrument called SPIDER that would measure the polarization of the microwave background, and thus reveal the work of gravitational waves in the early universe. If he were to get SPIDER onto one of the first operational launches of a super-pressurized balloon, as he hopes to in a few years' time, he thinks such measurements might provide conclusive proof of cosmological inflation - and thus scoop a proposed but not-yet-funded space mission, the Inflation Probe, which is unlikely to see space much before the end of the next decade.

Academics welcome the rapid conceptto-completion arc of balloon experiments not just as a way of flying equipment sooner, but also as a ready-made system for minting PhDs. "The timescale of building a balloon instrument, flying it, and getting data, is a timescale that a grad student can see from beginning to end," says Martin Israel, an 


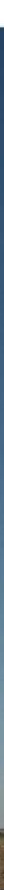

astrophysicist at Washington University in St Louis who is chairing a scientific ballooning planning report for NASA due later this year. The importance of that fertile training ground is not to be underestimated, says Swordy, who laments the "armies" of NASA scientists who sit behind comsputers but know little about building instruments. "We have to preserve a cadre of people who know how to put together instruments for the future."

\section{Lift-off}

At 07:00, during a long lull in the breeze, everyone around the test balloon puts in earplugs. Cobble opens valves on the helium truck and with a high-pitched hiss the gas snakes its way up tubes and into a balloon. Not yet into the super-pressurized ballon, but into a tow balloon attached to the top which lifts the main balloon up. Then 900 cubic metres of helium is introduced into the main balloon, enough to give it the anti-gravitational equivalent of a small car's weight in lift. Twenty minutes later, Cobble, riding at the front of Big Bill, pulls a lever and releases the balloon from a spring-loaded pin. Two dozen weathered faces, with shaded eyes, follow it up until it disappears in the glare of the still-low sun (see 'Up, up and away').

Its charge discharged, the CSBF team relaxes. But the engineers who designed and built the balloon are still on tenterhooks. At ground level the balloon is far from fully expanded; it is supposed to take on its designed pumpkinoid shape only in the much lower pressure of the stratosphere. But its predecessors have failed to do so. Since 2001, something odd has been happening on the test flights; the balloons, as they have risen, have never fully expanded. Material has remained folded in on itself in wrinkled clefts that look like Pac-Man or the S-shaped stitches on a baseball. That leads to instability of a sort that rules the balloons out for any practical work.

Structural engineers were called in to model the problem. They found that there was too much material in between the longitudinal tendons at the balloons' poles. As a result of this, the balloons naturally tended to fold in on themselves to reduce stress, says Henry Cathey, a NASA engineer at the Physical Science Laboratory of New Mexico State University in Las Cruces. "Some people have the perception: 'It's just a balloon. How hard can it be?' But it's a complicated structure."

In the hangar, the engineers watch live video from two cameras pointed up at the underbelly of the balloon from the gondola below. Its posterior blossoms like a flower. As the balloon rises at 18 kilometres per hour, wrinkle after wrinkle disappears. Except for one, at two o'clock on the balloon's downturned face. The engineers urge the recalcitrant cleft on:

"Come on. Come on."

"Give the dog a bone."

Finally, just as the balloon reaches its target height of about 30 kilometres, the last cleft relaxes; relief spreads through the room as everyone claps and shakes hands. The balloon floats west for an hour before the team triggers a tear in one of its panels. The engineering payload and its parachute drop toward the Capitan Mountain Wilderness of the Lincoln National Forest, more than 100 kilometres away, and land safely, dangled over a barbed wire fence and a rancher's trees — the balloon drifts on 20 kilometres downwind. The crucial goal of a fully puffed-up deployment has been achieved. In August, the balloon programme will ramp up for a bigger test: a super-pressure balloon the size of the Titanic (which is still much smaller than the zero-pressure balloons now in use). In December, Ball and his team will fly another of the same size from Antarctica in hope of breaking the 42-day duration record. In 2010, if all goes well, a balloon three times bigger will be flown, one capable of lifting an instrument payload weighing a tonne, and some small payloads will be tested. Routine flights could start in 2011.

The balloon programme office has requested that NASA officials start a dedicated line of funding for scientists seeking to build balloon-borne instruments, because some competitions for astrophysics funding at present only consider satellite missions. Cathey has no doubt that there will be an appetite. "This is the \$2.99 16-ounce steak that nobody knows about," he says. Today's test brings that steak a good step further towards the table.

That calls for celebration: but not today. At the end of July about 40 CBSF employees will head to Shreveport, Louisiana, for three days of horse racing, gambling and golf. "This is when we will celebrate," says Ball. "Not on campaigns. We're steely eyed balloon guys in the field." After the adrenaline rush of the morning, Cobble heads off alone to Fred's Restaurant for a hamburger before retiring to the Billy the Kid motel. He deserves a nap.

Eric Hand covers the physical sciences for Nature from the Washington DC office. 